\title{
Solid-state reduction of an ilmenite concentrate with carbon
}

\author{
by A. Bhalla*, C.S. Kucukkargoz*, and R.H. Eric*
}

\section{Synopsis}

The solid-state reduction of ilmenite concentrate with graphite was studied under argon atmosphere at temperatures between $1050^{\circ} \mathrm{C}$ and $1350^{\circ} \mathrm{C}$. The rate of reduction increased with increasing temperature and decreasing particle size, with the maximum extent of reduction found to be $80 \%$ at $1350^{\circ} \mathrm{C}$ with a particle size in the range of $-106+90 \mu \mathrm{m}$. The activation energy for the reduction reaction was calculated to be $257 \mathrm{~kJ} / \mathrm{mole}$. The trivalent iron oxide was reduced first to divalent iron oxide and then to metallic iron. An annular ring of a partially reduced oxide phase containing metallic nuclei was formed around the core of ilmenite, which grew in size as the original ilmenite core shrank with progressive reduction. The reduction of titanium dioxide also took place during this stage, which produced the Magnéli oxides in the form of $\mathrm{Ti}_{n} \mathrm{O}_{2 n-1}$. The metallic phase had very high $\mathrm{Fe}$ and low Ti contents throughout the reduction, whereas the partially reduced oxide phase adjacent to the metallic phase was high in Ti and depleted in Fe. The metallic phase globules formed during this stage were small and are considered suitable only for leaching and not for other concentration processes. The core of the particle generally retained the composition of the original ilmenite. The purpose of this work was to remove iron and increase the titanium oxide content of the ilmenite to produce a high-titanium containing charge for subsequent smelting.

Keywords

ilmenite, carbon, solid-state reduction, activation energy.

\section{Introduction}

The titanium-bearing minerals ilmenite $\left(\mathrm{FeTiO}_{3}\right)$ and rutile $\left(\mathrm{TiO}_{2}\right)$ are the primary natural raw materials used in industry to produce titanium metal and titanium-based products. The common titanium-bearing minerals are ilmenite, rutile, anatase, brookite, leucoxene, arizonite, and perovskite. Although the formula of ilmenite is commonly expressed as $\mathrm{FeTiO}_{3}$, the mineral can accommodate $\mathrm{Mn}$ and $\mathrm{Mg}$, which are chemically bound in the form of $(\mathrm{Fe}, \mathrm{Mn}, \mathrm{Mg}) \mathrm{TiO}_{3}$. Ilmenite concentrate can also contain $\mathrm{Fe}_{2} \mathrm{O}_{3}$ and $\mathrm{Al}_{2} \mathrm{O}_{3}$ in addition to the physically separable oxides such as $\mathrm{SiO}_{2}$ and $\mathrm{CaO}$. The crystal structure of ilmenite is an ordered derivative of the corundum structure with a trigonal-rhombohedral symmetry. $\mathrm{Fe}^{2+}$ and $\mathrm{Ti}^{4+}$ ions occupy the octahedral sites, leaving the tetrahedral sites unoccupied. In each $\mathrm{FeTiO}_{3}$ unit, there are three $\mathrm{O}^{2-}$ ions creating three octahedral sites, two of which are occupied by $\mathrm{Fe}^{2+}$ and $\mathrm{Ti}^{4+}$ (Wilson et al., 2005).

The Ti-0 system is complex, involving various $\mathrm{Ti}_{x} \mathrm{O}_{y}$ phases with $y / x$ ratios varying from 2 to 1.0. The general chemical formula representing the Magnéli oxides is interpreted in the form of $\mathrm{Ti}_{n} \mathrm{O}_{2 n-1}$ where $n$ ranges from 4 to 10 . The crystalline structures of $\mathrm{Ti}_{2} \mathrm{O}_{3}$, $\mathrm{Ti}_{3} \mathrm{O}_{5}$, and $\mathrm{Ti}_{5} \mathrm{O}_{9}$ are trigonal, monoclinic, and triclinic respectively. At higher temperatures, the Magnéli phases decompose to form a pseudobrookite solid solution (Pesl, 1997).

The methods used to produce titanium and titanium-based products from titaniumcontaining ores involve various pyrometallurgical, electrochemical, and hydrometallurgical processes. There are two main methods used in industry by which ilmenite is upgraded to prepare a feedstock that is later chemically treated to produce pure $\mathrm{TiO}_{2}$. In the first method, a mixture of metallic iron and rutile is produced in the solid state, whereas in the second method, a titania-rich slag and metallic iron are produced in the liquid state (Zietsman and Pistorius, 2004). In both methods, the reduction of ilmenite is considered an important step that requires a detailed knowledge of the mechanism of reduction with carbonaceous reducing agents under both inert and reducing gas atmospheres.

El-Guindy and Davenport (1970) found that the reduction of ilmenite was initiated at the contact between solid carbon and ilmenite particles, which controlled the reduction in the temperature range $860-1020^{\circ} \mathrm{C}$. The reduction was carried out by $\mathrm{CO}$ due to its high rate of regeneration through the reaction between graphite and $\mathrm{CO}_{2}$ at temperatures above $1020^{\circ} \mathrm{C}$. The diffusion of $\mathrm{CO}$ through the product layer was found to be the ratecontrolling step. In a study conducted by Wouterlood (1979), the ilmenite was reduced with char instead of solid carbon so that the reduction conditions would closely simulate plant conditions. The simulation conditions were complicated by the regeneration of $\mathrm{CO}$

\footnotetext{
* School of Chemical and Metallurgical Engineering. University of the Witwatersrand, Johannesburg, South Africa.

(C) The Southern African Institute of Mining and Metallurgy, 2017. ISSN 2225-6253. This paper was first presented at the Heavy Minerals Conference 'Expanding the Horizon', 16-17 August 2016, Sun City, South Africa.
} 


\section{Solid-state reduction of an ilmenite concentrate with carbon}

through reaction between carbon and $\mathrm{CO}_{2}$ as well as by the presence of hydrogen in the char. To overcome this difficulty, additional experiments were conducted using CO directly as the reducing gas. The results indicated that ferric iron was reduced to ferrous iron in the first, fast reduction stage and the ferrous iron was reduced to metallic iron in the second, slower reduction stage. Application of kinetic models proved that the unreacted core model (mixed control) was the most representative model.

Grey, Jones, and Reid (1973) identified the sequence of reduction as being reduction of $\mathrm{Fe}^{3+}$ to $\mathrm{Fe}^{2+}$ in the first stage and to $\mathrm{Fe}$ (metal) in the second stage, followed by the reduction of $\mathrm{TiO}_{2}$ to the lower oxide forms represented by $\mathrm{Ti}_{n} \mathrm{O}_{2 n-1}$ in the final stage. Merk and Pickles (1988) indicated that the metallic shell which was formed around the ilmenite grain due to the reduction of iron oxides by $\mathrm{CO}$ in the temperature range $500-1100^{\circ} \mathrm{C}$ inhibited CO diffusion in later stages and played an important role in the kinetics of reduction. Welham and Williams (1999) proposed that the reduction of ilmenite proceeded rapidly to form metallic iron and rutile. The rutile was then reduced to the lower oxides in the form of $\left(\mathrm{Ti}_{n} \mathrm{O}_{n-1}\right)$, culminating in a more stable oxide, $\mathrm{Ti}_{3} \mathrm{O}_{5}$. The formation of TiC was observed at $1100^{\circ} \mathrm{C}$, but this was favoured only at higher temperatures. Wang et al. (2008) identified the reaction products as mostly reduced iron, iron carbide, rutile, reduced rutile, and reduced rutile in solid solution with $\mathrm{Ti}_{3} \mathrm{O}_{5}$. The reaction rate was controlled by chemical reaction at lower temperatures and by diffusion through the product layer at higher temperatures. Sai (2008) applied various mathematical models based on selected data obtained from operational practices conducted in a rotary reactor, in which ilmenite was reduced with char. The ratecontrolling step was identified as solid-solid reaction during the initial stages and CO diffusion through the product layers during the later stages of reduction.

In a recent study (Lobo, Kolbeinsen, and Seim, 2013), the gaseous prereduction of ilmenite was studied using natural gas as the main reductant. It was shown that the iron oxides in ilmenite were reduced more effectively in the presence of hydrogen compared to $\mathrm{CO}$. The shrinking core model with multi-interfaces was found to represent the reduction behaviour of the titanium oxides.

Preliminary results on the kinetics and mechanism of ilmenite reduction with carbon reported by Kucukkaragoz and Eric $(2005,2006)$ indicated the strong effect of temperature and particle size on the reduction rate.

The objective of the present work is to study the reduction sequence of ilmenite by carbon; in particular, to define the reduction stage during which the majority of the iron oxide is reduced to the alloy phase before any significant reduction of the titanium oxide in the solid state. The relative (preferential) reduction of iron oxides over titanium oxides becomes important (Pistorius, 2002). The aim is to arrive at a product that has two physically separable phases-namely the metallic phase containing most of the iron, and the partially reduced oxide phase containing most of the titanium present in the ore. The subsequent step then involves the development of a suitable process for separating the metallic phase from the titanium oxide phase in the solid state.

\section{Experimental}

\section{Apparatus}

The thermogravimetric apparatus consisted of a vertical tube furnace, an electronic balance attached to a computer, a temperature controlling unit, a deoxidation furnace, and a gas regulator (manometer) unit for controlling the reaction gas atmosphere. The details of the experimental set-up can be found elsewhere (Soykan, Eric, and King, 1991). The furnace, which enclosed an alumina reaction tube, was heated using a molybdenum wire heating element. The temperature of the hot zone (reaction zone) was controlled by a B-type thermocouple ( $\mathrm{Pt}-6 \% \mathrm{Rh} / \mathrm{Pt}-30 \% \mathrm{Rh}$ ) within a range of $2^{\circ} \mathrm{C}$; the temperature was checked with another B-type thermocouple positioned at the hot zone. The molybdenum heating element was protected from oxidation by purging anhydrous $\mathrm{NH}_{3}$, which decomposed to nitrogen and hydrogen at reaction temperatures. An alumina pedestal attached to an electronic balance with a sensitivity of $\pm 0.1 \mathrm{mg}$ was used to position the crucible in the reaction zone. The mass change with respect to time was transmitted by the electronic balance and recorded on the computer. The system was closed and sealed with an expandable rubber bellows fitted between the work tube and the balance case before the work tube was purged with argon.

\section{Procedure}

A South African ilmenite concentrate was used in the experiments. The composition, as provided by the plant, is given in Table I. The sample was crushed, ground, and screened into three particle size groups: $-125+109 \mu \mathrm{m}$, $-109+90 \mu \mathrm{m}$, and $-90+63 \mu \mathrm{m}$. Graphite was ground and screened to the same particle sizes as the concentrate splits. The samples were prepared by mixing $4.5 \mathrm{~g}$ of ilmenite concentrate with $3.5 \mathrm{~g}$ of graphite, which was $50 \%$ in excess of the stoichiometric requirement to form $\mathrm{Fe}_{3} \mathrm{C}$ and $\mathrm{TiC}$ (according to the expected reaction). The furnace was heated to the required temperature, and each sample was placed in an alumina crucible and positioned on top of the pedestal which was attached to the balance. The expandable rubber bellows was connected to form a sealed zone between the work tube and the balance, and the reaction tube was purged with argon at a rate of 1 litre per minute for 15 minutes. The sample was then lifted over a period of around 5 minutes and located in the reaction zone under sealed conditions. The start of each experimental run was recorded as the zero-time for reaction as soon as the sample reached the reaction zone, and the recording of mass with respect to time was started by the computer. A series of experiments was conducted to study the influence of temperature and particle size on the reduction process at temperatures ranging from $1050^{\circ} \mathrm{C}$ to $1350^{\circ} \mathrm{C}$.

Another series of experiments was conducted by reacting the samples of $-106+90 \mu \mathrm{m}$ particle size at $1350^{\circ} \mathrm{C}$ to identify the phases formed at different stages of reduction. Each experimental run was conducted until a predetermined mass change, corresponding to the target reduction percentage, was observed. The mass change curves were examined to determine the regions indicating different reduction rates. The reduction stages were identified with the support of the analytical results obtained by scanning electron microscopyenergy-dispersive X-ray spectrometry (SEM-EDX) and X-ray diffractometry (XRD).

Table I

Chemical analysis of ilmenite concentrate

\begin{tabular}{|c|c|c|c|c|c|c|c|}
\hline & $\mathrm{TiO}_{2}$ & $\mathrm{FeO}$ & $\mathrm{Fe}_{2} \mathrm{O}_{3}$ & $\mathrm{Al}_{2} \mathrm{O}_{3}$ & MnO & $\mathrm{MgO}$ & $\mathrm{SiO}_{2}$ \\
\hline Mass $\%$ & 46.30 & 34.20 & 12.30 & 0.80 & 1.20 & 0.40 & 2.30 \\
\hline Mole \% & 48.35 & 39.68 & 6.43 & 0.65 & 1.41 & 0.83 & 2.65 \\
\hline
\end{tabular}




\section{Solid-state reduction of an ilmenite concentrate with carbon}

\section{Analytical work}

Each of the reacted samples was divided into two parts. One part was mounted in bakelite, polished, and examined by SEM and the other was subjected to XRD for phase identification. Point analysis for the distribution of elements was conducted by SEM-EDX.

\section{Stoichiometric calculations}

The samples were prepared so as to contain $50 \%$ excess C calculated on the basis of the stoichiometric mass of carbon required for completion of the following reduction reactions:

$$
\begin{aligned}
& \mathrm{TiO}_{2}+3 \mathrm{C} \rightarrow \mathrm{TiC}+2 \mathrm{CO} \\
& 3 \mathrm{Fe}_{2} \mathrm{O}_{3}+11 \mathrm{C} \rightarrow 2 \mathrm{Fe}_{3} \mathrm{C}+9 \mathrm{CO} \\
& 3 \mathrm{FeO}+4 \mathrm{C} \rightarrow \mathrm{Fe}_{3} \mathrm{C}+3 \mathrm{CO}
\end{aligned}
$$

The mass change recorded during an experiment was assumed to represent the mass of $\mathrm{CO}$ evolved from the sample as a result of reactions [1], [2], and [3]. The reduction percentage was calculated using Equation [4]:

$$
\text { Reduction } \%=\frac{\text { Mass of CO }}{\text { Mass of oxygen } * \frac{28}{16}} * 100
$$

where mass of oxygen indicates the total mass of removable oxygen present in the reducible oxides in the original ilmenite concentrate under the experimental conditions.

\section{Results and discussion}

The kinetic data obtained in the experimental work is presented in the form of reduction curves plotted as percentage reduction against reaction time. The kinetic curves indicating the influence of temperature and particle size on the reduction rate are given in Figures 1 and 2 respectively.

The rate and extent of reduction, as expected, increased with increasing temperature and decreased with increasing particle size. The differences in rates were noticeable at all temperatures and particle size ranges, and the results indicate a strong influence of temperature and particle size on the reduction rate.

\section{Mechanism of reduction}

A series of experiments was conducted by reducing $-106+90$ $\mu \mathrm{m}$ particle size samples at $1350^{\circ} \mathrm{C}$ and stopping the reaction at specific points representing varying degrees of reduction. The reduction curves obtained are presented in Figure 3.

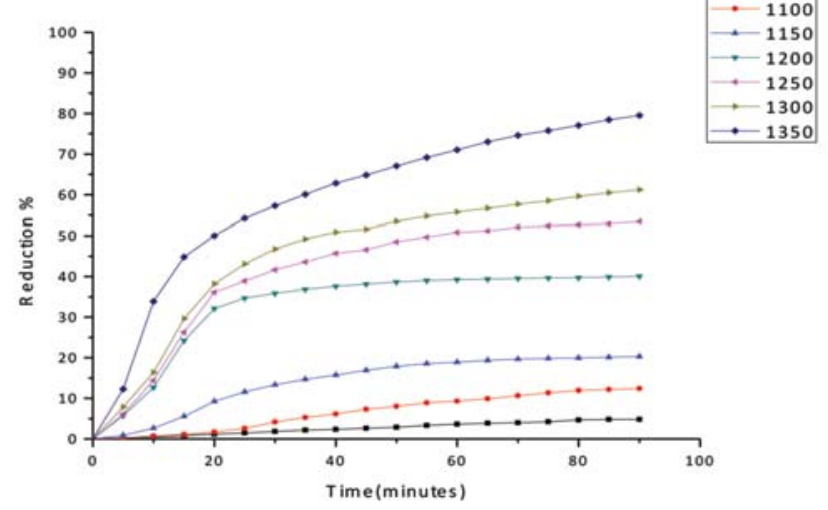

Figure 1-Effect of temperature $\left({ }^{\circ} \mathrm{C}\right)$ on reduction rate at particle size $-106+90 \mu \mathrm{m}$
The phases formed in the reacted samples were examined by SEM and analysed by EDX to obtain the elemental point analysis. The SEM images and the elemental analytical results are given in Figures 4 to 11. The reduced samples were also analysed by X-ray diffractometry to identify the phases formed during reduction, as illustrated in Figure 12. The phases detected are given in Table III.

Formation of metallic iron was first seen at $11 \%$ reduction (Figure 4 ). The metallic phase and the partially reduced oxide phase containing $\mathrm{Ti}_{n} \mathrm{O}_{2 n-1}$ were detected between 11 and 40\% reduction. The partially reduced oxide phase with a high titanium content and very low iron grew in size as the core of the particle shrank at the later stages of reduction.

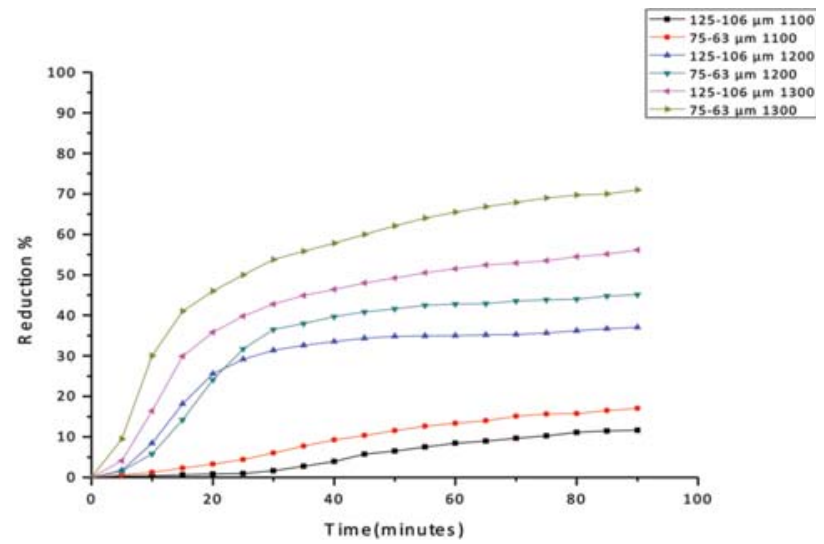

Figure 2-Effect of particle size on reduction rate at $1100^{\circ} \mathrm{C}, 1200^{\circ} \mathrm{C}$, and $1300^{\circ} \mathrm{C}$

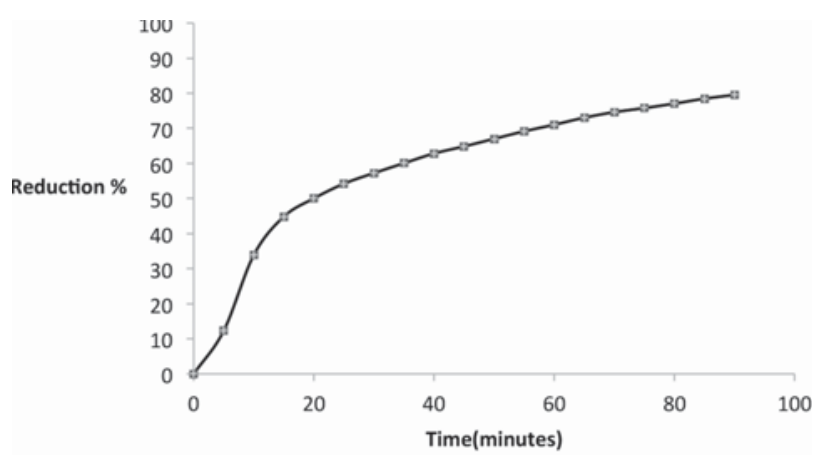

Figure 3-Reduction curve for $-106+90 \mu \mathrm{m}$ sample at $1350^{\circ} \mathrm{C}$

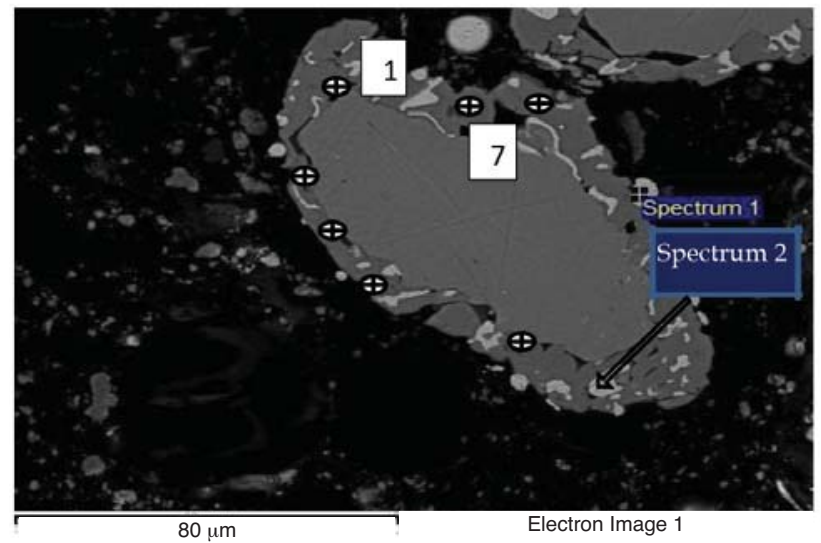

Figure 4-SEM backscattered image of particle at $11 \%$ reduction at $1350^{\circ} \mathrm{C}(-109+90) \mu \mathrm{m}$. Spot number (1-7) on reduced oxide phase (anticlockwise). Spectrum 1 and 2 on metal phase 


\section{Solid-state reduction of an ilmenite concentrate with carbon}

According to the results, the metallic phase formed during the initial reduction stages had a high iron content and low titanium content, whereas the oxide phase region adjacent to the metallic phase had a high titanium content and low iron content.

Table /I

SEM-EDX analysis of metal phase at spectrum points 1 and 2, Figure 4

\begin{tabular}{|l|c|c|c|}
\hline Spectrum no. & Ti (mass \%) & Fe (mass \%) & C (mass \%) \\
\hline 1 & 1.12 & 80.14 & 18.18 \\
2 & 1.49 & 80.14 & 18.18 \\
\hline
\end{tabular}

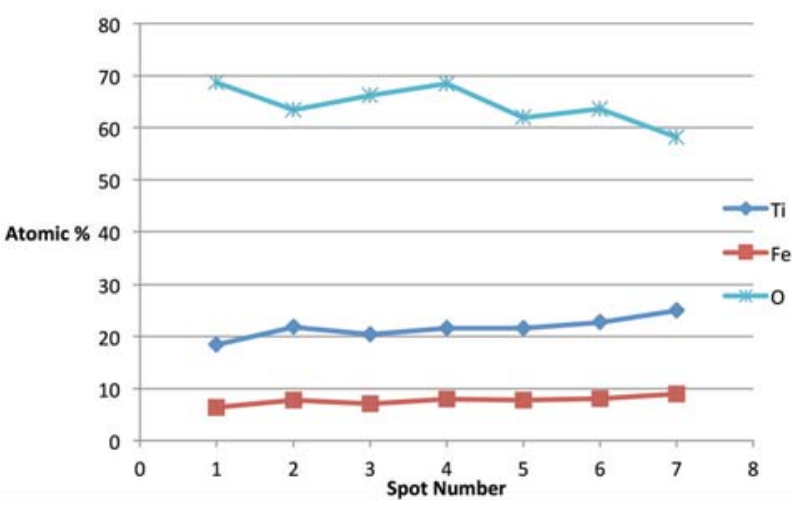

Figure 5-EDX elemental analysis of reduced oxide phase at spot points $1-7$ in Figure 4

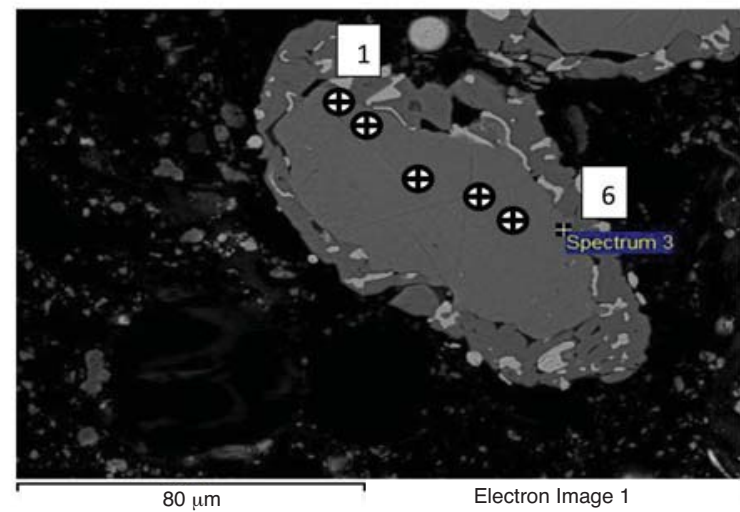

Figure $6 a-B a c k s c a t t e r e d$ SEM image of particle at $11 \%$ reduction at $1350^{\circ} \mathrm{C}(-109+90 \mu \mathrm{m}$ fraction). $\oplus$ Spot number 1-6 antiockwise

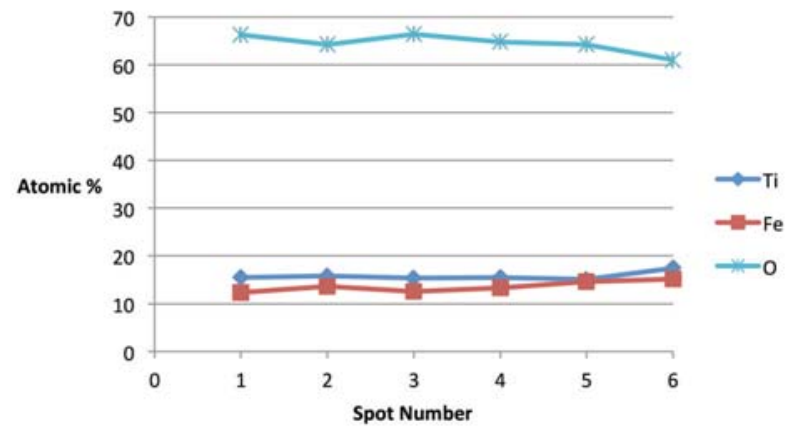

Figure $6 \mathrm{~b}-$ SEM-EDX analysis of reduced oxide phase/ilmenite at spot points in Figure 6a

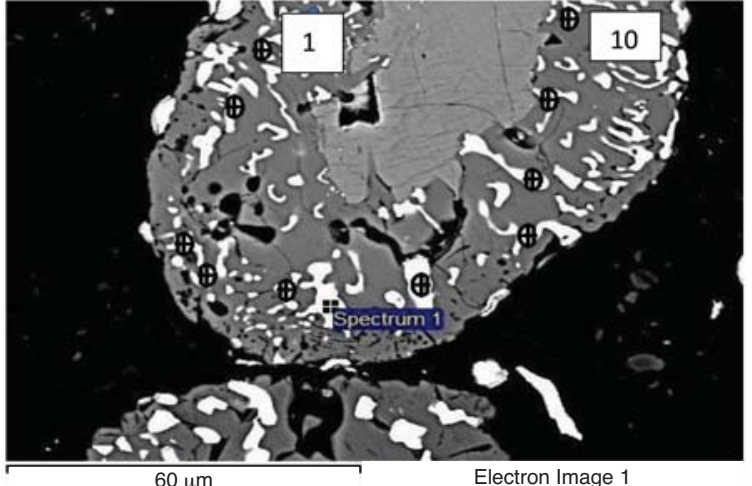

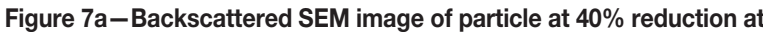
$1350^{\circ} \circ \mathrm{C}(-109+90 \mu \mathrm{m}$ fraction) $\oplus$ Spot number $1-10$ anticlockwise

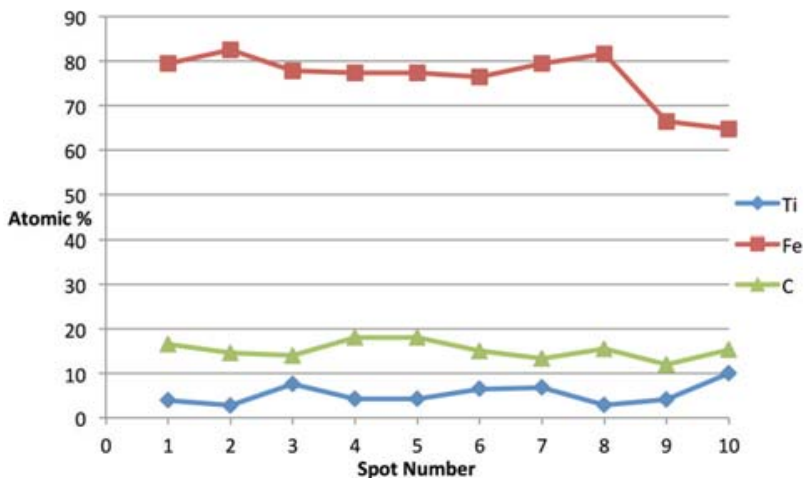

Figure 7b-SEM-EDX analysis of metal phase (spots 1-10) across the particle in Figure 7a

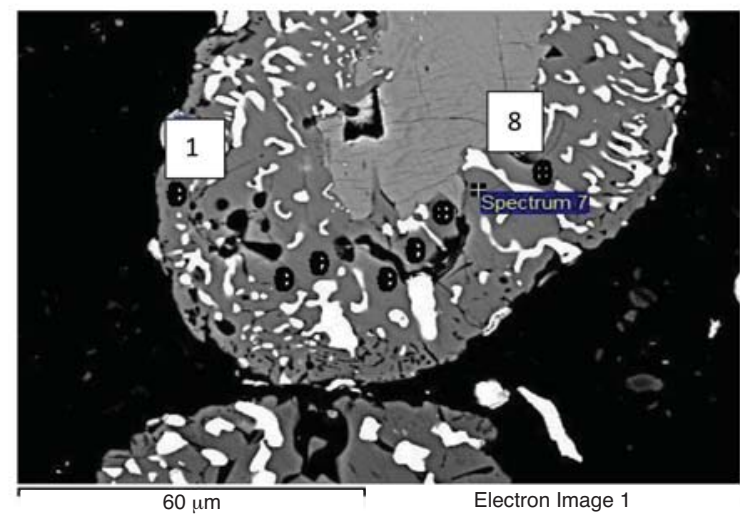

Figure $8 a-B a c k s c a t t e r e d$ SEM image of particle at $40 \%$ reduction at $1350^{\circ} \mathrm{C}(-109+90 \mu \mathrm{m}$ fraction). $\oplus$ Spot number 1-8 anticlockwise)

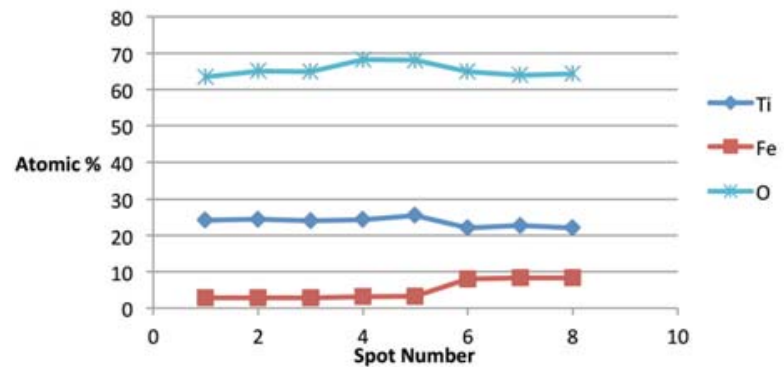

Figure $8 \mathrm{~b}-$ SEM-EDX analysis of reduced oxide phase at spot points across the particle in Figure $8 \mathrm{a}$ 


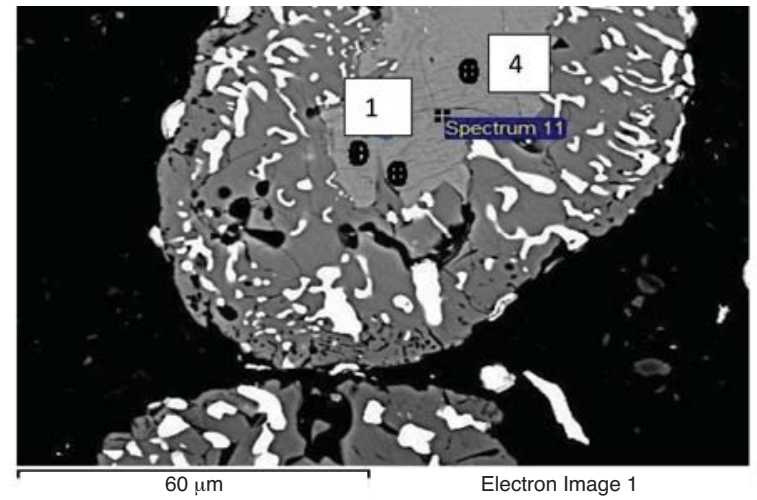

Figure $9 \mathrm{a}-\mathrm{SEM}$ image of particle at $40 \%$ reduction at $1350^{\circ} \mathrm{C}(-109+$ $90 \mu \mathrm{m}$ fraction. $\oplus$ Spot numbers 1-4 anticlockwise

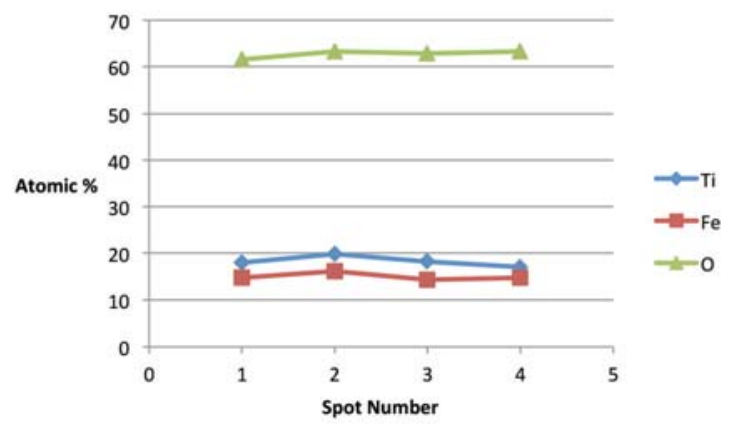

Figure $9 b-S E M-E D X$ analysis of the core ilmenite at spot points in Figure 9a

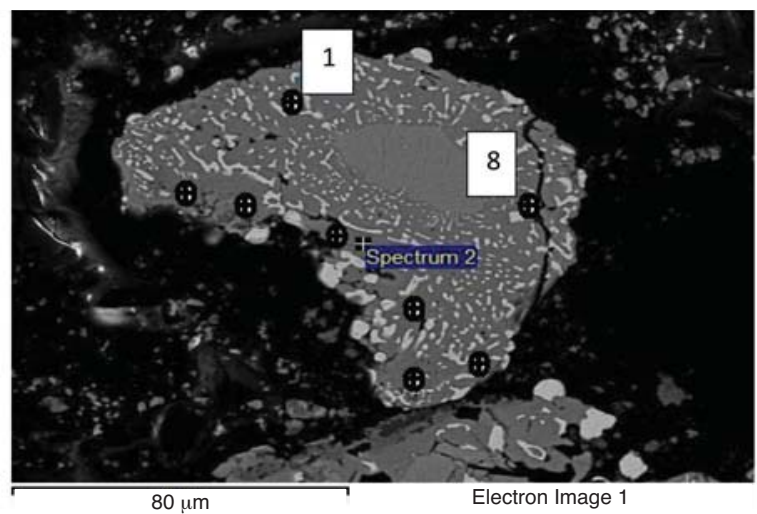

Figure $10 a-B a c k s c a t t e r e d$ SEM image of particle at $61 \%$ reduction at $1350^{\circ} \mathrm{C}(-109+90 \mu \mathrm{m}$ fraction). $\oplus$ (Spot numbers $1-8$ anticlockwise

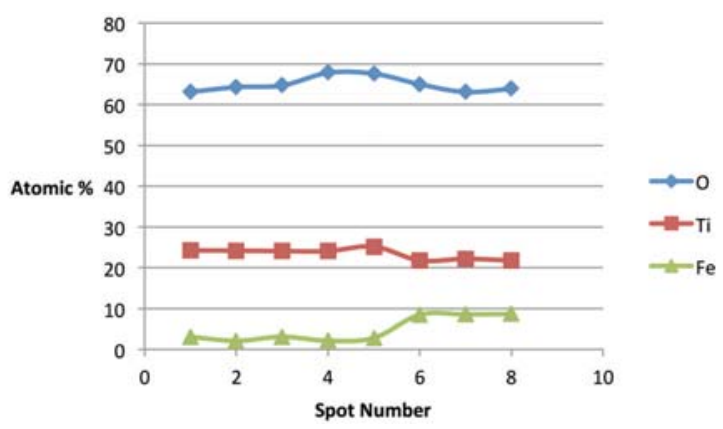

Figure 10b-SEM-EDX analysis of the partially reduced oxide phase surrounding the core across the particle in Figure 10a
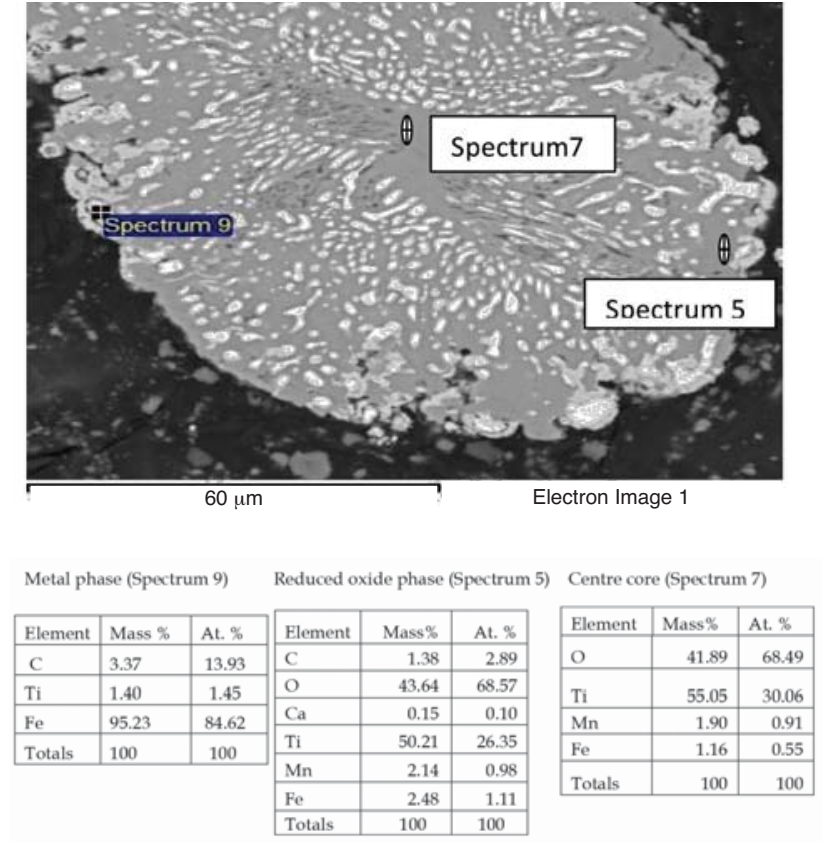

Figure 11-SEM image and EDX analysis (at spot points) of particle at $80 \%$ reduction at $1350^{\circ} \mathrm{C}(-109+90 \mu \mathrm{m}$ fraction $)$

\section{Stages of reduction}

In the literature, the reduction of ilmenite concentrate with carbon is reported to take place in the following sequence (Pesl, 1997):

$$
\begin{aligned}
& \mathrm{Fe}_{2} \mathrm{O}_{3} \rightarrow \mathrm{Fe}_{3} \mathrm{O}_{4} \rightarrow \mathrm{FeO} \rightarrow \mathrm{Fe}(\text { metal }) \\
& \mathrm{TiO}_{2} \rightarrow \text { Magnéli oxides }\left(\mathrm{Ti}_{7} \mathrm{O}_{13}-\mathrm{Ti}_{6} \mathrm{O}_{11}-\right. \\
& \left.\mathrm{Ti}_{3} \mathrm{O}_{5}-\mathrm{Ti}_{2} \mathrm{O}_{3}\right) \rightarrow \mathrm{TiO} \rightarrow \mathrm{Ti}
\end{aligned}
$$

The phases detected by XRD in the reacted samples at varying reduction percentages are presented in Table III. According to the results, Fe was first detected at $11 \%$ reduction, $\mathrm{Ti}_{7} \mathrm{O}_{13}$ at $40 \%$, both $\mathrm{Ti}_{6} \mathrm{O}_{11}$ and $\mathrm{Ti}_{3} \mathrm{O}_{5}$ at $60 \%$, and $\mathrm{TiO}$ at $80 \%$ reduction, which is in good agreement with the following theoretical approach based on stoichiometric calculations on the reduction of ilmenite concentrate with the given chemical composition.

Reduction of $\mathrm{Fe}_{2} \mathrm{O}_{3}$ to $\mathrm{FeO} \quad 0.0-4.0 \%$ reduction range Reduction of $\mathrm{FeO}$ to $\mathrm{Fe} \quad 4.0-34 \%$ reduction range

Reduction of $\mathrm{TiO}_{2}$ to $\mathrm{TiO} \quad 35 \%-65 \%$ reduction range Reduction of $\mathrm{TiO}$ to $\mathrm{Ti} \quad 65-100 \%$ reduction range

The highest reduction level obtained in the present work was $80 \%$, which indicates the possibility of partial reduction of TiO to $\mathrm{TiO}_{1-x}$ where $(x)$ is the corresponding mass of oxygen removed.

\section{First stage of reduction}

The initial reduction reaction started at the contact points between the solid carbon and the ilmenite particles. This was followed by the reaction between $\mathrm{CO}$ and ilmenite. The regeneration of $\mathrm{CO}$ through the Boudouard reaction became effective at temperatures above $1050^{\circ} \mathrm{C}$. Nucleation of a metallic phase took place at the most favourable sites on the surface of ilmenite particles during this stage, as can be observed in Figure 4. The high number of metallic nuclei covering the surface of the particle indicates a gaseous-type reaction. Mostly iron oxides were reduced in this stage as the metallic nuclei, which were rich in Fe and low in Ti, formed 


\section{Solid-state reduction of an ilmenite concentrate with carbon}

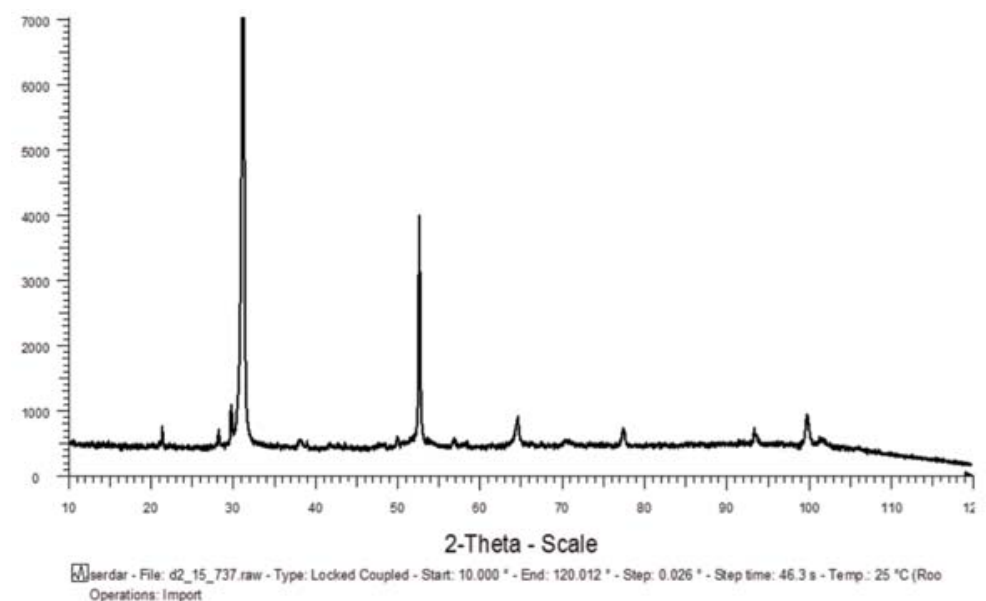

Figure $12-X$-ray diffraction of the sample at $50 \%$ reduction

\begin{tabular}{|l|c|c|}
\hline \multicolumn{2}{|l|}{$\begin{array}{l}\text { Table III } \\
\text { Phases detected by X-ray diffraction }\end{array}$} \\
\hline $\mathbf{T}\left({ }^{\circ} \mathrm{C}\right)$ & Reduction (\%) & Phases detected \\
\hline 1100 & 12 & $\mathrm{C}, \mathrm{FeTi}_{2} \mathrm{O}_{5}, \mathrm{TiO}_{2}, \mathrm{Fe}$ \\
1200 & 40 & $\mathrm{C}, \mathrm{Ti}_{7} \mathrm{O}_{13}, \mathrm{Fe}, \mathrm{Fe}_{3} \mathrm{C}$ \\
1300 & 60 & $\mathrm{C}, \mathrm{Fe}_{3} \mathrm{C}, \mathrm{Ti}_{6} \mathrm{O}_{11}, \mathrm{Ti}_{3} \mathrm{O}_{5}$, \\
1350 & 80 & $\mathrm{C}, \mathrm{Fe}_{7}, \mathrm{TiO}_{3}$ \\
\hline
\end{tabular}

and grew in size as the reduction progressed. During the initial stages of reaction (until 35\% reduction), a high concentration gradient of iron was developed due to reduction, which was the driving potential for iron diffusion across the particle. As the reduction proceeded, most of iron was reduced to the metallic state, causing a change in the Fe concentration profile across the particle (Figure 10). The initial stages of partial reduction of titanium oxide also took place during this stage, and formed, together with the metallic nuclei, a shell of a partially reduced oxide phase covering the core of the ilmenite particles as can be seen in Figure 4 . This stage took place between zero and $35 \%$ reduction and involved the part of the reduction during which the reduced oxide phase, together with the metallic nuclei, grew in size until the shell reached a certain thickness. The reduction rate was likely influenced by the formation and growth of the metallic nuclei, which was completed within this stage as seen in Figures $6 a$ and $7 a$.

\section{Second stage of reduction}

This stage took place at greater than $35 \%$ reduction, during which the shell of the partially reduced oxide phase, together with the already formed metallic nuclei, grew in size as the core ilmenite phase shrank. Theoretically, the reduction mechanism involved steps such as the mass transfer of the reactants to the reaction interface, reaction between the oxides and the CO prevailing at the interface, and the mass transfer of products from the reaction interface. The reduction reactions took place at the interface between the partially reduced oxide and ilmenite. Microscopical examination of the reduced particles revealed that each particle retained its original shape and size during the course of reduction. The removal of oxygen from the oxide phase therefore created a porous structure that allowed the passage of $\mathrm{CO}$ to, and $\mathrm{CO}_{2}$ from, the reaction interface. Removal of oxygen also resulted in a higher oxygen concentration in the unreduced ilmenite than in the partially reduced oxide, thus causing the transfer of oxygen to react with $\mathrm{CO}$ at the reaction interface.

SEM-EDX analysis indicated the possibility of the mass transfer of the reaction elements due to their high concentration gradients through the product layers across the particle. During the later stages of reduction, the original ilmenite was reduced almost completely to the partially reduced oxide phase containing most of the titanium oxides present in the original ilmenite, as can be seen in the microstructures and elemental analysis in Figure 11.

\section{Kinetics of reduction}

Examination of the representative reduction curve in Figure 3 reveals that the reduction process was characteristically separable into different stages, with each stage representing a different reduction rate. The first stage of reduction was defined as the linear part of the curve between zero and 35\% reduction, and the second stage as the part of the curve representing $35 \%$ reduction and above. These stages are proposed to represent a fast initial stage followed by a slower second stage.

The activation energy for the first stage of reduction $(0-$ $35 \%$ reduction) can be calculated according to the procedure described below.

The temperature dependence of the rate of a chemical reaction can be expressed by the Arrhenius equation:

$$
k=A e\left(\frac{-E_{A}}{R T}\right)
$$

where $k$ is the reaction rate constant, $A$ is a frequency factor $\left(\mathrm{s}^{-1}\right), R$ is the gas constant $(\mathrm{J} / \mathrm{mol} . \mathrm{K}), T$ is temperature (kelvin), and $E A$ the activation energy (J/mol).

The calculation procedure follows that of El-Guindy and Davenport (1970) and Kekkonen, Xiao, and Holappa (1995). The following assumptions were made for calculation of the activation energy:

The activation energy is valid for the reduction stage between zero and approximately $35 \%$ reduction, during which only iron oxide was reduced

The set of kinetic data taken from the reduction curves obtained at $1050^{\circ} \mathrm{C}, 1100^{\circ} \mathrm{C}$, and $1150^{\circ} \mathrm{C}$ (Figure 1) was used in the activity energy calculations. 


\section{Solid-state reduction of an ilmenite concentrate with carbon}

Taking the logarithm of each side of Equation [7] yields:

$$
\ln (k)=\ln (A)-\left(E_{A} / R\right)\left(\frac{1}{T}\right)
$$

which is a straight line with a slope of $-E_{A} / R$. Rate constant $(k)$ values were derived from the straight line portions of the kinetic curves given in Figures 1 for the first stage of the reduction. The slopes of the straight lines representing $\ln k$ versus $1 / T$ were used to calculate the average activation energy for the reduction reaction. In this work, the $\ln (k)$ and $1 / T$ values were substituted into Equation [8] in order to calculate the activation energy (EA) for the reduction reaction.

Using the experimental data given in Figure 1 for temperatures of $1050^{\circ} \mathrm{C}, 1100^{\circ} \mathrm{C}$, and $1150^{\circ} \mathrm{C}$, the $\ln (\mathrm{k})$ vs $1 / T$ curves were plotted and the slopes of the straight line sections of Figure 13 were used to calculate the average activation energy as $257 \mathrm{~kJ} / \mathrm{mole}$ for the initial stages of reduction (zero to $35 \%$ reduction). This value was found to be close to the activation energy value reported in the literature as $64 \mathrm{kcal} / \mathrm{mole}$ (El-Guindy and Davenport, 1970).

\section{Conclusion}

The reduction rate increased with increasing temperature and decreasing particle size. The metallic phase contained high $\mathrm{Fe}$ and low Ti values, whereas the oxide phase adjacent to the metallic phase contained high titanium oxide and low iron oxide.

The reduction of ilmenite proceeded through stages during which iron oxides were first reduced to form metallic iron and then to form iron carbides, whereas titanium oxides were reduced to form $\mathrm{Ti}_{n} \mathrm{O}_{2 n-1}$ during the initial stages with the possible formation of lower oxides at the later stages. The core of the particle (the original ilmenite grain) retained its composition with slight reduction of both iron and titanium oxides at the initial stages of reduction, and was reduced partially at the later stages.

The metallic nuclei formed in the partially reduced oxide phase were very small and are therefore not considered suitable for separation by mineral concentration processes. The kinetics of reduction were greatly influenced by the formation and growth of metallic nuclei during the initial stages of reduction and by the mass transfer (diffusion) process at the later stages. The overall activation energy for the initial stages of reduction of ilmenite with carbon was calculated as $257 \mathrm{~kJ} / \mathrm{mole}$ in the temperature range 1050$1150^{\circ} \mathrm{C}$.

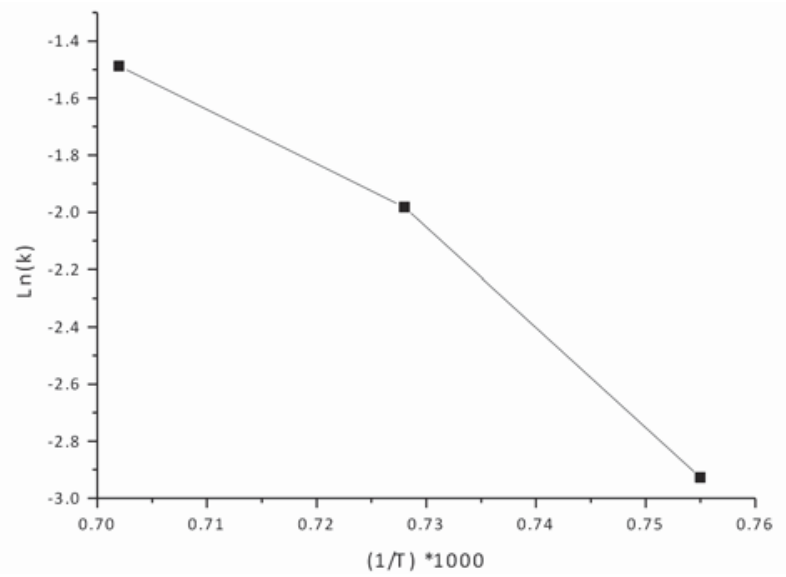

Figure $13-\ln (k)$ vs $1 / T$ curve

\section{Acknowledgements}

The authors wish to express their thanks to the School of Chemical and Metallurgical Engineering, University of the Witwatersrand for the laboratory facilities and the analytical services used. Thanks are also due to O. Netshifamadi, T.J. Molokwane, and S. Mokgadi (fourth-year project students) for carrying out some of the laboratory work, and to B. Nelwalani (SEM Technician) for the SEM-EDX analytical work.

\section{References}

EL-Guindy, M.I. and DAVENPoRT, W.G. 1970. Kinetics and mechanism of ilmenite reduction with graphite. Metallurgical Transactions, vol. 1. pp. 1729-1734.

GREY, I.E., JonES, D.G., and REID, A.F. 1973. Reaction sequences in the reduction of ilmenite. (1): Introduction. Transactions of the Institution of Mining and Metallurgy, vol. 82C. pp. 151-152.

KeKKonen, M., XiaO, Y., and HolapPA, L. 1995. Kinetic study on solid state reduction of chromite pellets. Proceedings of INFACON 7, Trondheim, Norway, June 1995. Tveit, H., Tuset, J.K., and Page, I.G. (eds.). Norwegian Ferroalloy Producers Research Organization (FFF).

KucukKaragoz, C.S. and ERic, R.H. 2005. Phase changes in solid state reduction of a natural ilmenite. Proceedings of Heavy Minerals 2005. Society for Mining, Metallurgy and Exploration, Littleton, CO. pp. 229-233.

KucuKKARAGoz, C.S. and ERIC, R.H. 2006. Solid state reduction of a natural ilmenite. Minerals Engineering, vol. 19, no. 3. pp. 334-337.

Lobo S., Kolbeinsen, L., and Seim, S. 2013. Pre-reduction of ilmenite with natural gas-model development and use. Proceedings of the 13th International Ferroalloys Congress: Efficient Technology in Ferroalloy Industry, Almathy, Kazakhhstan, 9-13 June 2013. pp. 857-868.

Merk, R. and Pickles, C.A. 1988. Reduction of ilmenite by carbon monoxide. Canadian Metallurgical Quarterly, vol. 27, no. 3. pp. 179-185.

Pesl, J. 1997. Thermodynamics and phase equilibria in the Fe-Ti-O System at $1500^{\circ} \mathrm{C}$ and $1600^{\circ} \mathrm{C}$ and metal-slag-equilibria pertinent to ilmenite smelting. PhD thesis, University of the Witwatersrand, Johannesburg.

Pistorius, P.C. 2002. The relationship between $\mathrm{FeO}$ and $\mathrm{TiO}_{2}$ in ilmenite smelter slags. Scandinavian Journal of Metallurgy, vol. 31, no. 2. pp.120-125.

SAI, P.S.T. 2008. Evaluation of mathematical models for the reduction of ilmenite with char in a rotary reactor. Journal of the Indian Institute of Chemical Engineers, vol. 50, no. 4. pp. 312-322.

Soykan, O., Eric, R.H., and King, R.P. 1991. Kinetics of reduction of the Bushveld Complex chromite ore at $1416^{\circ} \mathrm{C}$. Metallurgical and Materials Transactions B, vol. 22 B. pp. 801-810.

WANG, Y.M., YuAn, Z.F., Guo, Z.C., TAN, Q.Q., LI, Z.Y., and JiANG, W.Z. 2008 Reaction mechanism of natural ilmenite with graphite. Transactions of the .Nonferrous Metals Society of China, vol. 18. pp. 962-968.

Welham, N.J. and Williams, J.S. 1999. Carbothermic reduction of ilmenite $\left(\mathrm{FeTiO}_{3}\right)$ and rutile $\left(\mathrm{TiO}_{2}\right)$. Metallurgical and Materials Transactions $\mathrm{B}$, vol. 30B, December. pp. 1075-1081.

Wilson, N.C., Muscat, J., Mкhonto, D., Ngoepe, P.E., and Harrison, N.M. 2005. Structure and properties of ilmenite from first principles. Physical Review $B$, vol. B71, 075202 .

WOUTERLOOD, J.H. 1979. The reduction of ilmenite with carbon. Journal of Chemical Technology and Biotechnology, vol. 29. pp. 603-618.

Zietsman, J.H. and Pistorius, P.C. 2004. Process mechanisms in ilmenite smelting. Journal of the South African Institute of Mining and Metallurgy, vol. 104, no. 11. pp. 653-660. 